\title{
Application of energy-efficient methods in heating systems of industrial and public buildings
}

\author{
Igor Shelekhov ${ }^{1, *}$, Natalia Dorofeeva $^{1}$, and Maximilian Shelekhov ${ }^{2}$ \\ ${ }^{1}$ Irkutsk National Research Technical University, 664074, Lermontov str., 83, Irkutsk, Russia \\ ${ }^{2}$ Thermostat Open Company, 664011, 8 March alley, 4/25, Irkutsk, Russia
}

\begin{abstract}
In this article, a comparative analysis of the application of the heat-storage method of heating separately and combined with the use of a traditional heating system and infrared heating devices is carried out. In the presented paper, the analysis of the results obtained by comparing the operation of a traditional heating system and a heating system based on the application of modern techniques and new patented devices is given on the example of concrete premises. The research has shown that due to the use of modern techniques, the microclimate parameters described by the recorded temperature values have been improved by $30-45 \%$, and the energy costs have been reduced by more than three times.
\end{abstract}

The main energy costs for the maintenance and operation of buildings are spent on the heating system. One of the main tasks in the application of the energy saving technologies is the rational use of the thermal energy. One of the main components of this task is to maintain a stable temperature in the heated premises or keep a stable temperature in their certain areas. This issue is especially relevant for industrial and public buildings, the active operation of which is carried out for 8-10 hours, and there are no the maintenance personnel in the buildings during the remaining time.

In turn, the building envelope has a large heat capacity, and its temperature is usually below the temperature inside the building and above the ambient temperature for 9 months a year. Lowering the temperature of the indoor air during non-working hours gives a very small economic effect. In this case, there is a significant decrease in the degree of comfort of people staying in the premises when they resume their work after a break. Since, usually in such buildings the area and heat capacity of the enclosing structures is significant, then it takes hours to return to the design temperature. A person is in a comfortable state not only when the air temperature corresponds to the existing norms, but also when radiation heat affects him. The use of a radiative type of heating alone does not solve the problem either, since in this case the air heats up from everything that radiates heat in the premises, therefore time is required to reach the needed air temperature. The use of the combined heating systems is the most optimal form of space heating. For this heating system, it is necessary to carry out the appropriate calculations and select the proper control algorithms.

\footnotetext{
* Corresponding author e-mail: promteplo@yandex.ru
} 
The review of the literature shows that the main scientific directions in the field of rational use of thermal energy in industrial and public buildings are the application of the volumetricspatial method of distribution of the thermal energy inside the building with the use of the heat-accumulated heating systems, and the application of the constructive-technical solutions of heating systems with the use of the infrared heating devices.

Of the total number of works in the field of heat-accumulated heating systems, it would be worth highlighting the work of the Academician of the NAS of Ukraine, Doctor of Technical Sciences, Professor Yu.M. Matsevityi [1]. Together with co-authors, he presented a comprehensive assessment of the energy and economic efficiency of various systems of the heat-accumulating heating. The paper also contains a comparative analysis of the parameters of heat storage systems and traditional water heating systems. This article assesses the feasibility of using different types of heat accumulators to improve the energy efficiency of heat supply systems for civil buildings. Calculation of the energy efficiency of various types of heat-storage heating systems is made, and the advantages of these heating systems are shown in comparison with the traditional water heating system. The economic efficiency to be achieved, as well as the payback periods of such systems is demonstrated.

In the field of heating with the use of infrared heating, the works of V.Yu. Karnitskyi and V.S. Ushnikov [2] attract particular interest. It deals with the solution of this problem with the help of the infrared heating. Special attention is paid to the fact that infrared heating in the buildings with high heat protection uses more energy to maintain the required parameters of the microclimate.

Methods of rational combination of different types of heating are presented in the works of D.N. Vatuzov, S.M. Puring, E.B. Filatov [3] and Y. Cheng, J. Nin, N. Gao [4]. The authors point out that further complex work should be carried out in this direction.

It should be noted that, in general, the opinions of different authors differ only in the magnitude of the optimal fraction of radiant heat transfer. Some authors argue that it is necessary to ensure maximum heat release from the radiating devices heating [5 - 7]. Other authors believe that the fraction of radiant heat transfer should be at the level of $60-70 \%$ of the total values [8 - 10].

In our studies, we assumed that for the rational use of the thermal energy, it is necessary to take into account the heat-storage properties of all objects that are inside the premises, without abandoning the traditional system of district heating. Taking into account that the central heat supply system has its heat-storage characteristics, we have changed the main task of the central heat supply system. In our studies, the main task of heat supply is to provide standby heating of the premises with maintaining the temperature of the enclosing structures in the sense that the "dew point" is not reached and, accordingly, its maximum thermal insulation properties are ensured [11-15]. The main heating is carried out by the radiation heaters, which were manufactured in accordance with Patent No. 177507 "Heating device for the combined heating system of the premises with low thermal insulation" [16]. The peculiarity of the design of the heating device lies in the fact that in addition to the heating functions, it performs mutual control of the devices due to the change in the temperature coefficient, depending on the change of the external climatic factors.

Let us compare the results of the study of the distribution of temperature fields conducted in the premises heated by a conventional central heat supply system, and the results of the study of the distribution of temperature fields in the same premises after the installation of the new energy efficient localized heating system with the infrared heaters. The object of modernization is located at the address 3 a Novatorov Street in the city of Irkutsk. This is a wholesale storage of medicines, which consists of the three types of premises: a storage room of the size $10 \times 50 \mathrm{~m}^{2}$, an auxiliary room of the size $3 \times 5 \mathrm{~m}^{2}$, and a room for the personnel of the size $3 \times 4^{2}$. The storage of the medicinal products requires the creation of the localized zones 
with different climatic conditions in one of the rooms. The use of the infrared heaters for heating storage facilities is very promising.

To measure the parameters of the microclimate, standard techniques using thermoelectric sensors $[17,18]$, which were installed in pairs: one sensor fixing the temperature of the air, and the second one fixing radiation were utilized. Signals from the sensors were registered with the help of the standard software for the devices of the TRM138 brand produced by the company "OWEN" and supplied together with the devices. The software OWEN PROCES SMANAGER (OPM) is designed for the registration, display, and for data processing and analysis. The approximation of the results in the form of graphs of the distribution of temperature fields is imported into the Excel software.

Let us consider the results of the research. Prior to the implementation of measures to change the heating system in the premises under study, measurements of the parameters of distribution of the temperature fields were made, which are shown in the Figure 1.

a

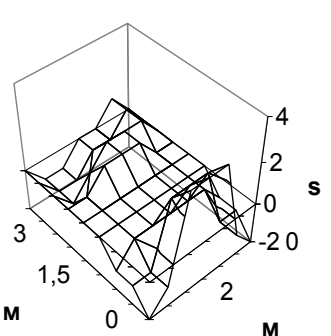

b

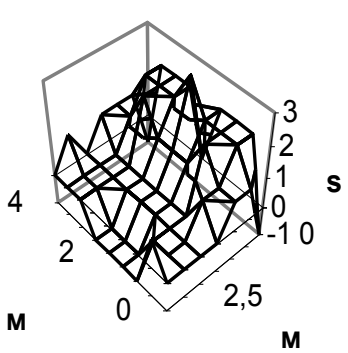

$\mathrm{c}$

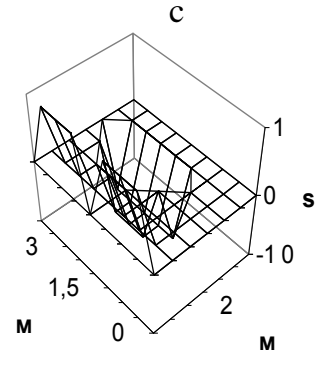

Fig. 1 Distribution of the temperature fields in the premises of a wholesale warehouse using the old heating system: a - a room for the personnel; b - auxiliary room, c - storage room.

When using the old heating system, in order to maintain the required temperatures in different areas of the investigated warehouse, in March 2016 was spent the following: heat energy (central heating) $30 \mathrm{Gcal}$; electricity (operation of the air conditioners) - 54 thousand $\mathrm{kWh}$ that led to the following costs: 33 thousand rubles for the heat energy and 189 thousand rubles for electricity; subtotal: 222 thousand rubles. In April 2016, 16.5 Gcal of the heat energy and 50 thousand $\mathrm{kWh}$ of electricity were used, which amounted to 18.15 thousand rubles for the thermal energy and 175 thousand rubles for electricity; subtotal: 193.15 thousand rubles. The TOTAL for the two months was 415.15 thousand rubles to maintain the required temperature regime.

The Figure 2 shows the distribution of the temperature fields after the change of the heating system, that is, after the installation of the new energy-efficient local heating system with infrared heaters. The first graph (a) shows how the distribution of temperature fields in the personnel room has changed. The area of distribution of the favorable microclimate conditions increased by $40 \%$. The second graph (b) shows the distribution of temperature fields in the auxiliary room. The area of distribution of the favorable microclimate conditions increased by $35 \%$. The third graph (c) shows that the distribution of temperature fields in the storage room, where medicines are stored, has also changed for the better. The area of favorable microclimate conditions increased by $45 \%$, in the area of direct storage of medicinal products, the microclimate conditions correspond to the existing requirements by $100 \%$.

The amount of material costs to change the heating system in 2016 was 200 thousand rubles. At the same time, the load on the central heating system was reduced to a minimum, and the use of the air conditioners was stopped by $90 \%$. 
a

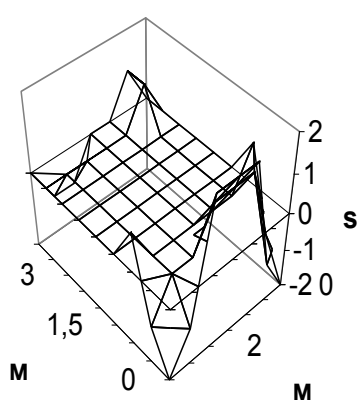

b

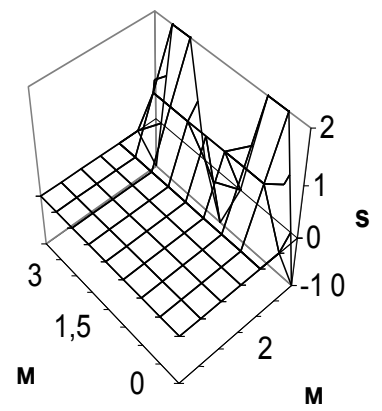

$\mathrm{c}$

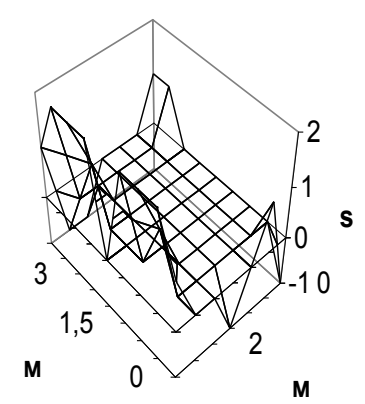

Fig. 2. Distribution of the temperature fields in the premises of a wholesale warehouse using the new heating system: $\mathrm{a}-\mathrm{a}$ room for personnel; $\mathrm{b}$ - auxiliary room, $\mathrm{c}$ - storage room.

After the heating system was renewed, in March 2017 the costs looked as following: thermal energy (central heating) - $5 \mathrm{Gcal}$; electric energy costs (infrared heaters) - 18 thousand $\mathrm{kWh}$. In money terms, this amounted to: 5.500 rubles for the thermal energy and 63.000 rubles for electricity. Subtotal: 68.5 thousand rubles. In April 2017, 3 Gcal of heat energy was spent; electric energy - 15 thousand $\mathrm{kWh}$, which amounted to 3.3 thousand rubles for the heat energy and 52.5 thousand rubles for electricity, subtotal: 55.8 thousand rubles. TOTAL for the two months - 124.3 thousand rubles.

Consequently, the payback period of the activities carried out at this specific facility at a price of 1.1 thousand rubles per $1 \mathrm{Gcal}$ was 1.5 months.

To date, a stock of theoretical justification and a large practical material is accumulated, the use of that allows reducing the cost of heating in the industrial and public buildings. These technologies are widely implemented in the economically developed countries. According to many experts, the rational energy use can save more than $40 \%$ of total energy consumption. Contrary to this, heating systems are not rationally calculated and installed. In the overwhelming majority it is done in contradiction to common sense that leads not to the saving but to the considerable overconsumption of energy. The cost of maintaining the microclimate in the investigated premises of the wholesale warehouse decreased more than 3 times, herewith the general conditions of the microclimate improved significantly.

In conclusion, it is necessary to say that when implementing new technological solutions, it is necessary to introduce complex design of the systems providing microclimate conditions in the premises for various purposes. The ratio of convection and radiation components of heating should be calculated by the qualified specialists taking into account the characteristics of the premises and the features of its operation.

\section{References}

1. Yu. M. Matsevity, N. G. Ganzha, A. V. Khimenko, Energy Saving, Power Engineering, Energy Audit of NTU KhPI, 10 (2011)

2. V. Yu. Karnitsky, VS Ushnikov, Izvestia of the Tula State University. un., 12, 3 (2016)

3. DN Vatuzov, SM Purring, EB Filatova, Engineering-builds. Herald of Pri Caspi, 2, 3 (2013)

4. Y. Cheng, J. Nin, N. Gao, Building and Environment, 47 (2012)

5. J. Chen, C. Poon, Building and Environment, 44 (2009)

6. A. I. Shchelokov, E. B. Filatova, Bulletin of the Samara State Tech. Univ., 2 (2011) 
7. The economic effect of the use of infrared heaters: calculation of costs (http://www.teplo.ufakit.ru/? Partid = 56)

8. N. I. Kurilenko, R. R. Davlyatchin, A. N. Ermolaev, Engineering Herald of the Don, 2 (2015)

9. J. Carmody, S. Selkowitz, D. Arasteh, L. Heschong, Residential windows: a guide to new technologies and energy performance (New York, W.W. Norton, 2007)

10. M. Tenpieric, W. Van der Spoel, H. Cauberg, Journal of Building Physics, 31 (2008)

11. J. Dieckmann, ASHRAE Journal, 8 (2008)

12. I. Yu. Shelekhov, T. I. Shishelova, E. I. Smirnov, V. P. Inozemtsev, Bulletin of the Mordovian University, 27(2) (2017)

13. V. Lapinskiene, V. Martinaitis, The framework of an optimization model for building envelope (2013)

14. A. V. Bogoviz, S. V. Lobova, Y. V. Ragulina, A. N. Alekseev, International Journal of Energy Economics and Policy, 8(3), 67-75 (2018)

15. V. Granadeiro, J. P. Duarte, J. R. Correia, V. M. S. Leal, Integrating architectural design systems and energy simulation (2013)

16. I. Yu. Shelekhov, I. V. Shelekhova, M. I. Shelekhov, E. I. Smirnov, V. P. InoZemtsev, K. P. Kashko, Patent for Utility Model No. 177507, Bulletin, 7 (2018)

17. V. N. Bogoslovsky, Building Thermophysics (Moscow, 2013)

18. A. V. Bogoviz, S. V. Lobova, Y. V. Ragulina, A. N. Alekseev, International Journal of Energy Economics and Policy, 7(5), 93-101 (2017) 